D. V. Kiseleva

A. N. Zavaritsky Institute of Geology and Geochemistry of Urals Branch of Russian Academy of Sciences, 15 Akademika Vonsovskogo, 620016, Ekaterinburg, Russia Kiseleva@igg.uran.ru

\title{
Matrix-matched calibration in LA-ICP-MS of silicate, phosphate and carbonate minerals: application of G-Probe samples
}

Laser ablation (LA) sampling provides fast microelement ICP-MS analysis of a wide range of solid materials without their dissolution, thus decreasing contamination from water and reagents as well as reducing polyatomic isobaric interferences from acid solutions. However, the issue of matrix-matched calibration becomes crucial for LA-ICP-MS due to differences in behaviour during laser interaction and evaporation of solid samples. There are several approaches to LA calibration: simultaneous supply of standard solutions into a spray chamber; calibration using a set of NIST 61x synthetic glasses and glasses prepared from natural rocks and minerals (basalt, nephelinite, etc.) or pressed synthetic samples (calcium carbonates, phosphates and sulphides produced by USGS). A set of natural glasses for microanalysis is available from the International Association of Geoanalysts (IAG) in co-operation with the USGS. The G-Probe proficiency testing programme has been operating since 2008 and deals with solid samples for microanalysis (LA-ICP-MS, EPMA, EDS-SEM). A number of samples of different compositions were distributed: BBM-1G and BSWIR-1G natural basaltic glasses, GSM-1 gabbro; NIST SRM-based basaltic and diabase glasses; GP-MACS synthetic pressed calcium carbonate, GP-MAPS phosphate and some others. The aim of the present work was to estimate the LA-ICP-MS analysis quality using matrix-matched calibration with G-probe samples of various composition. All G-Probe samples were analysed using an ELAN 9000 Q-ICP-MS combined with a LSX-500 (Nd:YAG, 266 nm) laser ablation system. For silicate rocks, TB-1 basaltic glass was used for calibration; the remaining samples were analysed as unknowns. MAPS-4 calibration material were used for phosphate rock analysis. A combination of external matrix-matched calibration and internal normalisation was used for calculating element concentrations. LA-ICP-MS analysis quality was estimated using z-scores. Most of the results obtained were in a good agreement with assigned values.

Keywords: laser ablation; inductively coupled plasma mass-spectrometry; geological glasses; matrix-matched calibration; internal standard

Received: 23.12.2019. Accepted: 20.02.2020. Published: 31.03.2020.

(C) Kiseleva D. V., 2020 


\section{Introduction}

Laser ablation (LA) sampling in inductively coupled plasma mass spectrometric (ICP-MS) analysis allows the rapid analysis of the trace element composition of solids to be carried out without their dissolution. At the same time, the contamination from the reagents used is minimised, and polyatomic isobaric interferences arising due to the presence of acid solutions are significantly reduced [1]. LA-ICP-MS is widely applied in the studies of microobjects with high spatial resolution, individual mineral grains, and spatial distributions of trace elements.

However, the issue of matrix-matched calibration becomes crucial for LA-ICP-MS of solids due to differences in behaviour during laser interaction and evaporation of solid samples, especially when using $193 \mathrm{~nm}$ excimer and 213 and $266 \mathrm{~nm}$ Nd:YAG lasers [2].

To date, there are several widely practiced approaches to constructing calibration curves in the analysis of solid samples of various compositions using laser ablation sampling: some include the simultaneous supply of aqueous calibration solutions to the spray chamber of a mass spectrometer $[3,4]$; others use synthetic glasses of the NIST SRM 61x series (manufactured by the National Institute of Standards and Technology, USA), as well as glasses made by fusion of natural rocks and minerals (basalt, nephelinite, etc.) or pressed synthetic non-silicate samples (calcium carbonates and phosphates, sulphides, US Geological Survey, USA).

The first approach leads to a complication of design features (for example, the manufacturing, often in-house, of chambers with additional inputs for solutions, the connection of an additional gas for spraying), as well as the formation of polyatomic isobaric interferences from the solvents (water and acids). The use of synthetic glasses for calibration provides a certain unification of the results obtained, but can be justified only in some cases (for example, for the analysis of silicate samples), while their composition does not reflect the natural sample composition with their wide range of trace element content [5]. For example, about 33 microelements with concentrations from 15 to $80 \mu \mathrm{g} / \mathrm{g}$ are certified in the most widespread NIST SRM 612 glass, which is insufficient when analysing the entire variety of rocks and minerals.

Taking into account the above-mentioned, the most acceptable way to calibrate a mass spectrometer when analysing solid samples is to use matrix-matched calibration samples, and NIST SRM 612 glasses to optimise the analytic parameters of the device (adjusting the interface, monitoring the level of oxides, etc.).

The range of solid reference materials (RM) of natural composition has expanded significantly at the moment: The US Geological Survey produces 4 natural basalt glasses and 1 nephelinitic glass, which are the melts of powdered BCR-2, BHVO-2, BIR-1, TB-1 and NKT-1 certified reference materials (SRM) [5], respectively, as well as synthetic pressed MACS-3 calcium carbonate and MAPS-4 phosphate and MASS-1 polymetallic sulphide.

The glass making procedure [5] involves the fusion of the powdered rock material in an oven in a platinum crucible at $1325-1645^{\circ} \mathrm{C}$ for $2-6$ hours with several stirrings with a platinum rod and subsequent rapid cooling in deionised water. The pieces of glass are then dried, fixed in epoxy resin and distributed to analytical laboratories. For pressed powdered sam- 
ples [6], a specially developed procedure of trace element co-precipitation with pure calcium carbonate or phosphate in a reaction vessel is used. The resulting suspension is powdered to less than $40 \mu \mathrm{m}$, dried at $110^{\circ} \mathrm{C}$ and pressed into pellets with a diameter of $19 \mathrm{~mm}$. The homogeneity and composition of the samples obtained is confirmed by a number of studies in USGS laboratories (XRF, LA-ICP-MS, EPMA, etc.). Thus, the samples described above are microanalytical reference materials (MRM), that is, they have passed the certification procedure and issued certificates with certified concentrations of major and trace elements.

An expanded set of natural glasses for microanalysis is presented as part of the GProbe interlaboratory testing programme, which combines the efforts of the US Geological Survey and the International Association of Geoanalysts (IAG).

The main idea of the programme is to analyse the samples of unknown composition sent to a number of interested laboratories around the world, after which the organisers provide the data on the composition of these samples and protocols summarising the results obtained by all participants, and evaluate the quality of analysis in a particular laboratory. G-Probe programme has been operating since 2008 and specialises in solid samples for microanalysis (LA-ICP-MS, EPMA, SEM-EDS); the number of participating laboratories has been ranged from 12 to 30 in various rounds with those providing the LA-ICP-MS results from 6 to 18, which reflects the complexity and specificity of mass spectrometric analysis of natural geological materials with high spatial resolution [7].

Since 2008, 13 samples of various composition and origin were distributed: natural basalt glasses based on samples taken by the USGS expeditions (BBM-1G, BSWIR-1G), gabbro (GSM-1); basalt glass based on the geological NIST SRM 688; glass based on the USGS W-2 diabase standard; SL factory soda-lime glass; synthetic pressed GP-MACS calcium carbonate and GP-MAPS calcium phosphate et al. Almost all G-Probe samples are prepared and analysed in USGS laboratories in accordance with the procedures adopted for microanalytical standard samples, and very often they become certified reference materials after processing the results provided by the G-Probe participants.

Since 2008, the laboratory of Physical and Chemical Methods of Investigation of Mineral Substance (IGG UB RAS) has been taking part in the G-Probe programme. The laboratory has all of the listed solid geological glasses and synthetic pressed pellets, as well as NIST SRM 612 glass.

The aim of the present work is to estimate the LA-ICP-MS analysis quality using matrix-matched calibration with G-probe samples of various composition.

\section{Experimental}

The following geological glasses and microanalytical reference materials were studied (Table 1).

LA-ICP-MS trace element analysis was carried out using an ELAN 9000 quadrupole mass spectrometer (PerkinElmer) with an LSX-500 laser ablation system

(Cetac, Nd:YAG laser with a wavelength of $266 \mathrm{~nm}$ ). The LA-ICP-MS analysis algorithm included daily tuning and selection of the operating parameters of the mass spectrometer using multi-element calibration solutions followed by laser ablation, while the ELAN 9000 operating condi- 
tions and gas flows were adjusted in accordance with the highest possible intensity signal at a minimum level of oxides (ThO/Th $\leq 0.8 \%)$ using NIST 612.

The isotopes analysed were: ${ }^{7} \mathrm{Li},{ }^{9} \mathrm{Be},{ }^{11} \mathrm{~B}$, ${ }^{45} \mathrm{Sc},{ }^{51} \mathrm{~V},{ }^{53} \mathrm{Cr},{ }^{55} \mathrm{Mn},{ }^{59} \mathrm{Co},{ }^{60} \mathrm{Ni},{ }^{65} \mathrm{Cu},{ }^{66} \mathrm{Zn}$, ${ }^{71} \mathrm{Ga},{ }^{74} \mathrm{Ge},{ }^{75} \mathrm{As},{ }^{85} \mathrm{Rb},{ }^{86} \mathrm{Sr},{ }^{89} \mathrm{Y},{ }^{90} \mathrm{Zr},{ }^{93} \mathrm{Nb}$, ${ }^{95} \mathrm{Mo},{ }^{109} \mathrm{Ag},{ }^{111} \mathrm{Cd},{ }^{115} \mathrm{In},{ }^{118} \mathrm{Sn},{ }^{123} \mathrm{Sb},{ }^{128} \mathrm{Te}$, ${ }^{133} \mathrm{Cs},{ }^{135} \mathrm{Ba},{ }^{139} \mathrm{La},{ }^{140} \mathrm{Ce},{ }^{141} \mathrm{Pr},{ }^{146} \mathrm{Nd},{ }^{147} \mathrm{Sm}$, ${ }^{153} \mathrm{Eu},{ }^{157} \mathrm{Gd},{ }^{159} \mathrm{~Tb},{ }^{163} \mathrm{Dy},{ }^{165} \mathrm{Ho},{ }^{167} \mathrm{Er},{ }^{169} \mathrm{Tm}$, ${ }^{172} \mathrm{Yb},{ }^{175} \mathrm{Lu},{ }^{178} \mathrm{Hf},{ }^{181} \mathrm{Ta},{ }^{184} \mathrm{~W},{ }^{205} \mathrm{Tl},{ }^{208} \mathrm{~Pb}$, ${ }^{209} \mathrm{Bi},{ }^{232} \mathrm{Th},{ }^{238} \mathrm{U}$.

The following LA operational parameters (Table 2) were used when analysing the samples of various compositions based on the previously obtained data taking into account the specific features of rock/mineral laser evaporation $[8,9]$.
LA-ICP-MS data were acquired in runs of up to 15 analyses. Each run started and ended with two data acquisitions on a calibration material. The 15 analysis limit ensured that calibration was performed on no more than about an hourly basis, in order to monitor and correct for the drift of the inter-element sensitivities (i.e., analyte-internal standard) with time.

Most often, for the quantitative LAICP-MS analysis, a combination of calibration by RM and internal standardisation is used [10], when the ratio of the analyte and the internal standard intensities is taken as the analytical signal. Since the addition of internal standards is not easily and routinely carried out with solid samples, naturally occurring elements are used as internal standards. These are elements that are found

Table 1

G-Probe samples and microanalytical reference materials used for the study

\begin{tabular}{|c|c|c|c|}
\hline $\begin{array}{c}\text { G-Probe round } \\
\text { number }\end{array}$ & Name & Material & Origin \\
\hline GP-5 & BBM-1G & Basalt & USGS \\
\hline GP-6 & BNV-1G & Basalt & NIST SRM 688 \\
\hline GP-8 & SL-1G & Soda-lime glass & Corning Glass Works, 1976 \\
\hline GP-10 & GP-MAPS & Calcium phosphate & USGS \\
\hline GP-11 & DVA-1G & Diabase & W-2 USGS SRM \\
\hline GP-12 & GSM-1G & Gabbro & $\begin{array}{l}\text { San Marcos Mountains, Southern } \\
\text { California Batholith, USA }\end{array}$ \\
\hline GP-14 & BBRZ-1G & Basalt & $\begin{array}{l}\text { BRP-1 SRM (University } \\
\text { of Campanias, Brazil) }\end{array}$ \\
\hline GP-15 & SyMP-1G & Syenite & SyMP-1 USGS SRM \\
\hline GP-16 & BSWIR-1G & $\begin{array}{l}\text { Mid-Ocean Ridge Basalt } \\
\text { (MORB) }\end{array}$ & $\begin{array}{l}\text { Southwest Indian Range, } \\
\text { the border of the African and } \\
\text { Antarctic Plates }\end{array}$ \\
\hline $\mathrm{RM}$ & MAPS- $4^{*}$ & $\begin{array}{l}\text { Calcium Phosphate with } \\
\text { trace elements }\end{array}$ & USGS MRM \\
\hline $\mathrm{RM}$ & $\mathrm{TB}-1 \mathrm{G}^{\star *}$ & Basalt & $\begin{array}{l}\text { TB-1 USGS SRM (Golden, } \\
\text { Colorado, USA) }\end{array}$ \\
\hline
\end{tabular}

${ }^{\star}$ Used for calibration for the analysis of phosphate rock samples.

${ }^{*}$ Used for calibration for the analysis of silicate rock samples. 
in both the samples and calibration material, and for which the concentrations are known in both materials [10]. The concentration of the internal standard can be obtained from an analysis using an alternative method (for example, EPMA, EDS-SEM) or from the known elemental stoichiometry when crystalline materials are analysed. Often, one of the major elements serves as the internal standard containing in the sample in sufficiently large quantities (e.g. silicon for silicate rocks, calcium and phosphorus for carbonate and phosphate minerals, zirconium, hafnium for zircons, etc.).

In this case, finding the analyte content in the sample is carried out according to the formula:

$$
\mathrm{C}_{s}^{a}=\frac{\left(I_{s}^{a}\right)^{\prime}}{\left(I_{c a l}^{a}\right)} \cdot \mathrm{C}_{c a l}^{a} \cdot K
$$

where $\left(I_{s}^{a}\right)^{\prime}=I_{s}^{a} / I_{s}^{i s}$ is the analyte relative intensity normalised to the internal standard intensity in the sample, both background subtracted, $\left(I_{\text {cal }}^{a}\right)^{\prime}=I_{\text {cal }}^{a} / I_{\text {cal }}^{i s}$ is the analyte relative intensity normalised to the internal standard intensity the in the calibration material, both background subtracted, $\mathrm{C}_{c a l}^{a}$ is the analyte concentration in the calibration material, $K=\mathrm{C}_{s}^{i s} / \mathrm{C}_{\text {cal }}^{i s}$ is the coefficient taking into account the ratio of the concentrations of the internal standard in the sample $\left(\mathrm{C}_{s}^{i s}\right)$ and the calibration material $\left(\mathrm{C}_{\text {cal }}^{\text {is }}\right)$.

Thus, the silicate samples were analysed using a TB-1G basalt glass for calibration with internal silicon standardisation. Phosphate sample was analysed using MAPS-4 synthetic phosphate RM for calibration and internal calcium standardisation.

Table 2

LA and ICP-MS operational parameters during the analysis of silicate and phosphate samples

\begin{tabular}{|c|c|c|}
\hline \multicolumn{3}{|c|}{ LA parameters } \\
\hline & Phosphate rocks [8] & Silicate rocks [9] \\
\hline Energy, mJ & 0.9 & 0.9 \\
\hline frequency $\mathrm{Hz}$ & 20 & 20 \\
\hline Spot diameter, microns & 50 & 50 \\
\hline Pulse Duration, ns & $<10$ & $<10$ \\
\hline \multicolumn{3}{|c|}{ ICP-MS parameters } \\
\hline RF power & \multicolumn{2}{|c|}{$1300 \mathrm{~W}$} \\
\hline Plasma Ar flow rate & \multicolumn{2}{|c|}{$161 / \mathrm{min}$} \\
\hline Auxiliary Ar flow rate & \multicolumn{2}{|c|}{$1.0 \mathrm{l} / \mathrm{min}$} \\
\hline Sample Ar flow rate & \multicolumn{2}{|c|}{$11 / \mathrm{min}$} \\
\hline \multicolumn{3}{|c|}{ Data acquisition parameters } \\
\hline Dwell time & \multicolumn{2}{|c|}{$8 \mathrm{~ms}$} \\
\hline Quadrupole settling time & \multicolumn{2}{|c|}{$1.5 \mathrm{~ms}$} \\
\hline Sweeps for total analysis & \multicolumn{2}{|c|}{480 ( 240 for background and 240 for ablation) } \\
\hline Sweeps per reading & \multicolumn{2}{|c|}{3} \\
\hline Points per peak & \multicolumn{2}{|c|}{1} \\
\hline Total analysis time & \multicolumn{2}{|c|}{$\sim 240 \mathrm{~s}$} \\
\hline
\end{tabular}




\section{Results and discussion}

Scoring and statistical analysis in GeoPT is undertaken according to the ISO 13528 Standard relating to statistical methods used in proficiency testing [11] based on the earlier recommendations of the IUPAC International Harmonised Protocol [12].

According to the GeoPT Protocol [13], the results of the analysis are evaluated using $\mathrm{z}$-scores in the form:

$$
\mathrm{z}=\left(\mathrm{x}_{\mathrm{i}}-\mathrm{x}_{\mathrm{pt}}\right) / \sigma_{\mathrm{pt}}
$$

where $x_{i}$ is the result of the analysis of a particular laboratory, $\mathrm{x}_{\mathrm{pt}}$ is the assigned value of the element content in the test sample, $\sigma_{\mathrm{pt}}$ is the corresponding standard deviation for proficiency testing (SDPT), or target precision, based on a GeoPT fitness for purpose criterion.

In the G-Probe programme, the values of element concentrations obtained during analysis in USGS laboratories, as well as the data from NIST SRM certificates (in case glass was fused from a standard sample), and results of analysis of bulk powder samples from previous rounds are taken as $\mathrm{x}_{\mathrm{pt}}$ assigned elemental content.

In the Protocol of the G-Probe programme, a model of the standard deviation dependency on concentration is adopted as an $\sigma_{\mathrm{H}}$ estimate of the target precision in the form of the Horwitz function [14]:

$$
\sigma_{\mathrm{pt}}=\sigma_{\mathrm{H}}=0.02 \cdot \mathrm{x}_{\mathrm{pt}}^{0.8495}
$$

where the values of concentrations and precision should be expressed in mass fractions (for example, $1 \mathrm{ppm}=10^{-6}$, $1 \%=0.01$ ); the coefficient $\mathrm{k}=0.02$ corresponds to the results of the second category of results - applied geochemistry.

Accordingly, a z-score outside the range \pm 3 implies that an unacceptable source of bias may be present in the participant's analytical system and that the need for remedial action should be considered.
Z-scores more extreme than \pm 2 carry the same message to a lesser degree [13].

However, an assumption has been made by [15] that the dependency of the standard deviation on concentration in the form of the Horwitz function used in the GeoPT programme does not take into account the main source of analytical errors due to the distribution of the component being determined in the sample, while determining trace elements additional errors in the measurement results contribute to the heterogeneity of the distribution. Thus, the dependence $\sigma_{\mathrm{H}}=f(\mathrm{x})$, based on approximation by the Horwitz function, is too strict for the determination of trace elements. The authors [15] have proposed the following approximations of the dependency of the permissible standard deviation for high and low concentrations:

$$
\begin{gathered}
\mathrm{S}=0.005 \cdot \mathrm{x}_{\mathrm{pt}}^{0.5} \text { if } \mathrm{x}_{\mathrm{pt}}>0.1 \% \\
\mathrm{~S}=0.035 \cdot \mathrm{x}_{\mathrm{pt}}^{0.8495} \text { if } \mathrm{x}_{\mathrm{pt}} \leq 0.1 \%
\end{gathered}
$$

The results of LA-ICP-MS analysis and $\mathrm{Z}$-scores are given in Supplementary Table S1. The measurement result is the mean value of two measurements performed on two different sample fragments each consisting of two parallel measurements.

For a number of samples studied (Table 1 ), the values of the $\mathrm{z}$-scores were calculated in accordance with the Protocol of the G-Probe programme, as well as the $z^{\prime}$ - scores using the dependency of the standard deviation for low concentrations $\mathrm{S}=0.035 \cdot \mathrm{C}^{0.8495}(\mathrm{C} \leq 0.1 \%)$ since almost all the concentrations of determined elements in studied samples were less than $0.1 \%$ [15].

Figure 1 shows the generalised distribution of a number trace elements depending on the $\mathrm{z}$-scores (a) and the $\mathrm{z}$ - - scores (b) for the samples studied. It can be seen that the results of the LA-ICP-MS analy- 
sis of most trace elements are satisfactory, a certain amount falls outside the range \pm 3 . When the quality assessment is performed using the z' - scores, a greater number of results are recognised as satisfactory, and only some elements still fall outside the range \pm 3 .

Most often, during LA-ICP-MS analysis of geological samples, a number of elements are of the greatest interest - these are the rare-earth elements (REE), yttrium, uranium, thorium and lead. To illustrate the quality of their analysis, $\mathrm{z}$ ( $\mathrm{z}^{\prime}$ ) plots were constructed (Fig. 2).

Figure 2 shows that when assessing the quality of analysis by the $z$ ' - scores, the vast majority of the results of the determination of REE, yttrium, uranium, thorium and lead fall within the range not exceeding \pm 2 with the insignificant number of outliers for SL-1G, SyMP-1G и BSWIR-1G, thus indicating the satisfactory results.

The outliers for SL-1G and SyMP-1G samples can be explained by its major element composition different from the TB-1G natural basaltic glass. SL-1G soda-lime glass contains $\sim 71 \%$ of $\mathrm{SiO}_{2}$, which is rather close to NIST SRM 612 glass (72\% $\left.\mathrm{SiO}_{2}\right)$. SyMP-1G syenite $\left(55.3 \% \mathrm{SiO}_{2}\right)$ has intermediate composition according to the igneous rock classification by silicon a

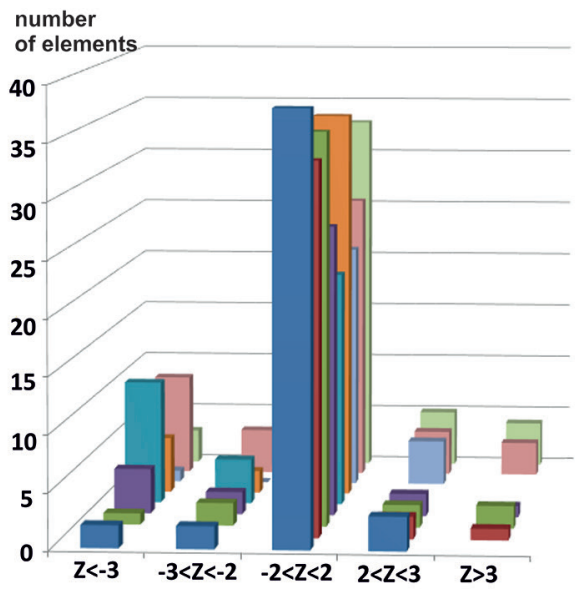

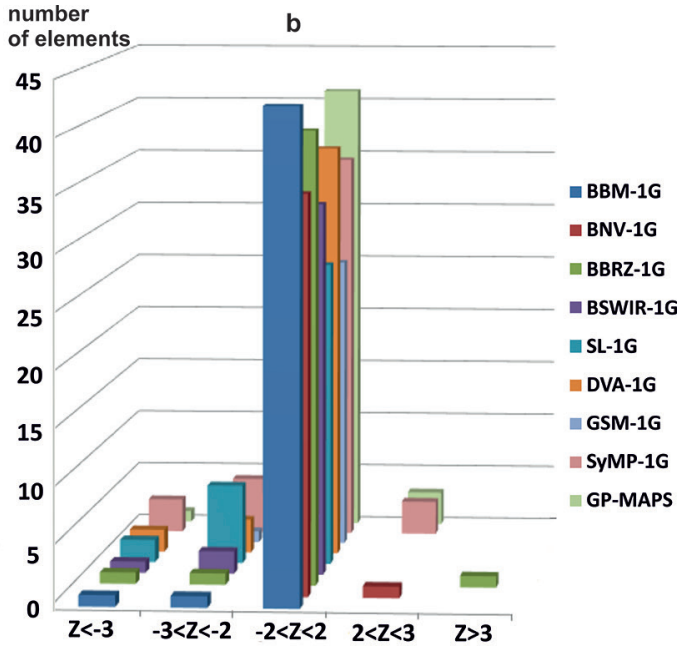

Fig. 1. Summary plots of element distribution versus z-scores (a) and z' - scores (b)
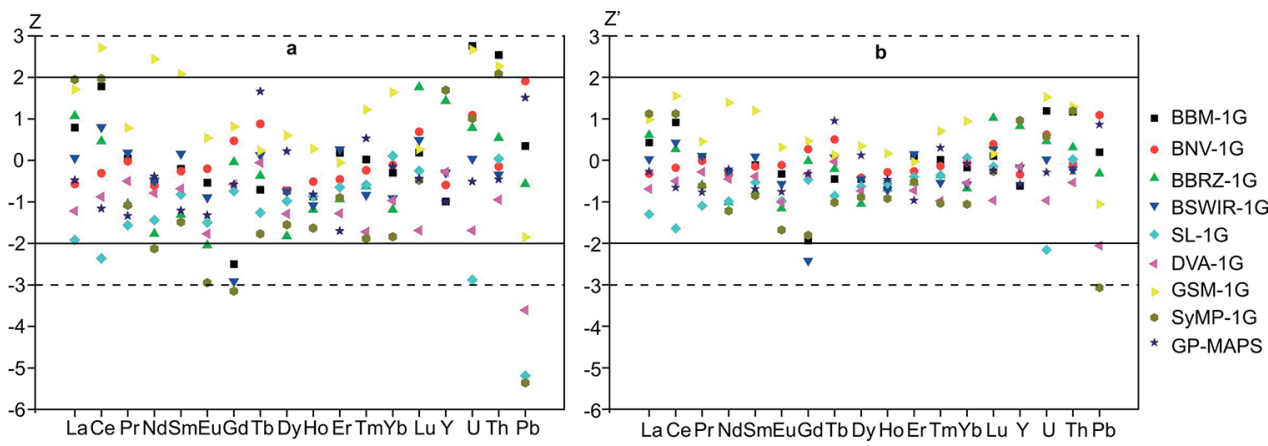

Fig. 2. z (a) and $\mathrm{z}^{\prime}$ (b) plots for REE, Y, U, Th, and Pb 
dioxide content $\left(52-63 \%\right.$ of $\mathrm{SiO}_{2}$ ), while all natural basaltic, gabbro and diabase glasses have mafic composition, and their silica content is generally $45-52 \%$. Thus, the difference in the composition of major elements especially if they are used as internal standards, can lead to the biased results. When analysing igneous rocks composed of silicate minerals, a careful selection of calibration materials should be performed taking into account their composition classified by silicon dioxide content - mafic, intermediate or felsic.

\section{Conclusions}

This study describes the matrixmatched calibration approach to the analysis of geological samples by LA-ICP-MS using the samples provided by G-Probe programme (International Association of Geoanalysts). A wide range of G-Probe samples with the composition of major elements (matrix) similar to natural geological objects (silicates, phosphates and carbonates) can be used as calibration samples especially in geoanalytical labo-

ratories in order to correct for differences in behaviour during laser interaction and evaporation of solid samples. The conducted evaluation of the analysis quality for a number of geological samples using $\mathrm{z}$-scores has proved that the combination of matrix-matched external calibration and internal standardisation in LA-ICP-MS microanalysis of rocks and minerals allows satisfactory results to be obtained for most of the determined elements.

\section{Acknowledgements}

The study was carried out at the Geoanalytic Collective Use Centre and supported by RSF grant No. 16-17-10283.

\section{References}

1. Jackson SE. The application of Nd:YAG lasers in LA ICP-MS. Ed. P. Sylvester. Laser ablation ICP-MS in the Earth Sciences: Principles and applications. Short Course Series. Mineralogical Association of Canada. 2001;29:29-45.

2. Jochum KP, Stoll B, Weis U, Jacob DE, Mertz-Kraus R, Andreae MO. Non-matrixmatched calibration for the multi-element analysis of geological and environmental samples using $200 \mathrm{~nm}$ femtosecond LA-ICP-MS: A Comparison with nanosecond lasers. Geostandards and Geoanalytical Research. 2014;38:265-92.

DOI:10.1111/j.1751-908X.2014.12028.x

3. O'Connor C, Sharp B, Evans P. On-line additions of aqueous standards for calibration of laser ablation inductively coupled plasma mass spectrometry: theory and comparison of wet and dry plasma conditions. J Anal At Spectrom. 2006;21:556-65. DOI: 10.1039/B600916F

4. Votyakov SL, Adamovich NN. O protsessakh lazernogo ispareniya i ispol'zovanii vodnykh standartov pri LA-ISP-MS-analize ryada mineralov [About the processes of laser evaporation and using of aqueous calibration solutions for LA-ICP-MS analysis of a number of minerals]. Litosfera. 2011;4:56-69. 
5. Jochum KP, Stoll B. Reference materials for elemental and isotopic analyses by LA (MC) - ICP - MS: successes and outstanding needs. Mineralogical Association of Canada. Short Course 40. 2008;40:147-68.

6. Jochum KP, Garbe-Schönberg D, Veter M, Stoll B, Weis U, Weber M, Lugli F, Jentzen A, Schiebel R, Wassenburg JA, Jacob DE, Haug GH. Nano-Powdered Calcium Carbonate Reference Materials: Significant Progress for Microanalysis? Geostandards and Geoanalytical Research. 2018;43(4):595-609.

DOI: 10.1111 /ggr.12292

7. Adamovich NN, Kiseleva DV. Mezhlaboratornyy kontrol' kachestva LA-ICP-MS mikroanaliza $\mathrm{v}$ ramkakh programmy testirovaniya geoanaliticheskikh laboratoriy G-Rrobe [Interlaboratory quality control of LA-ICP-MS microanalysis according to G-Probe proficiency testing programme for geoanalytical laboratories]. Ezhegodnik-2011. Tr. IGG UrO RAN. 2012;159:222-3.

8. Adamovich NN. Vozmozhnosti metoda mass-spektrometrii s induktivno svyazannoy plazmoy i lazernoy ablyatsiey dlya lokal'nogo opredeleniya mikroelementnogo sostava apatitov [The possibilities of LA-ICP-MS analysis of trace element composition of apatites with high spatial resolution]. Ezhegodnik-2012. Tr. IGG UrO RAN. 2013;160:309-13.

9. Adamovich NN, Glavatskikh SP, Votyakov SL. Issledovaniya osobennostey ispareniya silikatov, fosfatov i sul'fidov kak osnova dlya sozdaniya metodik lokal'nogo opredeleniya mikroelementnogo sostava v metode mass-spektrometrii s lazernoy ablyatsiey [The studies of evaporation of silicates, phosphates, and sulphides as a basis for LA methodologies of trace element analysis with high spatial resolution]. Ezhegodnik-2012, Tr. IGG UrO RAN. 2013;160:314-8.

10. Longerich HP, Jackson SE, Günther D. Laser ablation inductively coupled plasma mass spectrometric transient signal data acquisition and analyte concentration calculation. J Anal At Spectrom. 1996;11:899-904.

DOI: $10.1039 /$ JA9961100899

11. ISO 13528, 2015. Statistical methods for use in proficiency testing by interlaboratory comparison, Geneva: ISO; 2015.

12. Thompson M, Ellison SLR, Wood R. The international harmonised protocol for the proficiency testing of analytical chemistry laboratories. IUPAC Technical Report. Pure Appl. Chem. 2006;78:145-96.

DOI:10.1351/pac200678010145

13. Thompson M. GeoPT ${ }^{\mathrm{rm}}$. Protocol for the operation of proficiency testing scheme. International Association of Geoanalysts. 2018.

14. Horwitz W, Kamps LR, Boyer KW. Quality assurance in the analysis of foods for trace constituents. J. AOAC Int. 1980;63:1344-54.

15. Kuznetsova AI, Zarubina OV. Mezhlaboratornyy kontrol' kachestva pryamogo atomno-emissionnogo analiza s ispol'zovaniem serii gornykh porod programmy testirovaniya geoanaliticheskikh laboratoriy GeoPT [Interlaboratory quality control of direct atomic emission analysis using the series of rock samples of GeoPT proficiency testing programme for geoanalytical laboratories]. Analitika i kontrol'. 2005;3(9):230-9. 